\title{
A Rare Diagnosis in the Neck During Childhood: Congenital Chondrolipoma
}

\author{
Fulya ÖZER ${ }^{1}$, Nebil BAL ${ }^{2}$ \\ Departments of ${ }^{1}$ Otolaryngology Head and Neck Surgery and ${ }^{2}$ Pathology, Başkent University, Faculty of Medicine, ADANA, TURKEY
}

\begin{abstract}
Chondrolipomas are mesenchymal tumors that found as mature cartilage tissue in a fat tissue. A 2-year-old boy was seen with a complaint of a mass of the neck. On physical examination of the child, there was a one-centimeter mass above the sternocleidomastoid muscle on the lateral neck. Pathological examination of this mass after excision was reported as chondrolipoma. Chondrolipomas are seen mostly in the breast and in the adult. They are rare tumors of the head and neck area and seen mostly the in oral cavity here. This is the first case of chondrolipoma with this age and localization combination in the literature. Chondrolipoma should therefore also be considered in the differential diagnosis of congenital masses located at lateral cervical area.
\end{abstract}

Key Words: Congenital, Head and neck neoplasms, Childhood, Mesenchymal

\section{INTRODUCTION}

Chondrolipoma is a benign mesenchymal tumor where mature chondroid areas are observed as a result of cartilaginous metaplasia in lipoma (1). Chondrolipomas are most frequently seen in the breast and rarely in the head and neck region and are most commonly found in adults in the fifth and sixth decade $(2,3)$. Chondrolipoma has previously been identified in head and neck area in the childhood in two cases in the literature $(4,5)$. It is most commonly in the oral cavity and nasopharynx in the head and neck region and this is the first case in the literature it has involved the neck region soft tissue in a child. Although rare, chondrolipoma should be considered in the differential diagnosis of congenital lateral neck masses.

\section{CASE REPORT}

A boy aged 2 years and 7 months was brought to our clinic due to a pea-sized swelling of the right side of the neck that had been present since birth. The prenatal and postnatal history of the patient who was born as one of triplets with $\mathrm{C} / \mathrm{S}$ birth at 35 weeks and a birth weight of 1170 grams was unremarkable. Ear, nose and throat examination findings were normal and a mobile and palpable hard mass about $1 \mathrm{~cm}$ in diameter was located in the $1 / 3$ bottom part of the sternocleidomastoid (SCM) muscle on the right side of the patient's neck. A subcutaneous hyperechoic lesion $8 \mathrm{~mm}$ in diameter at the bottom level of the right SCM

(Turk Patoloji Derg 2017, 33:161-163)

Received : 15.03.2013 Accepted : 09.05.2013 compatible with a ruptured sebaceous cyst was reported in the ultrasound performed at the radiology department. Excision under sedoanalgesia was therefore planned. After an incision in the overlying skin, a lesion with a hard cream-colored capsule was totally removed over the SCM muscle. On macroscopic examination of the mass there was a gray cream-colored solid mass with semi-rigid appearance $0.8 \times 0.6 \times 0.4 \mathrm{~cm}$ in size and the histopathological examination revealed well-defined mature cartilage islands inside mature fat areas surrounded with a fibrous capsule. The diagnosis was chondrolipoma (Figure 1,2). No recurrence was observed in the post-operative 15-month follow-up.

\section{DISCUSSION}

A large group of lesions are included in the differential diagnosis of congenital childhood masses of the neck, especially in the lateral cervical region (6). Most of these lesions can be differentiated by their pathology (Table I). Muscular fibrosis due to birth trauma was thought to be present in this case at first with a solid mass of $1 \mathrm{~cm}$ on the SCM. However, the appearance during surgery, and the hard mass with a smooth surface that was encapsulated and yellow in color suggested intramuscular lipoma. Congenital masses of this kind that are localized at the lateral cervical spine region can be confused with an intramuscular lipoma and lesion named olive due to torticollis in the $\operatorname{SCM}(7,8)$.

Correspondence: Fulya ÖZER

Başkent Üniversitesi Tip Fakültesi,

Kulak Burun Boğaz Baş ve Boyun Cerrahisi, ADANA, TURKEY

E-mail: fdeveci06@hotmail.com Phone: +90 5335448054 
No torticollis was present in our case and the surgical observation and pathological diagnosis did not support an olive lesion due to torticollis. Chondrolipoma shows a different pathology appearance from intramuscular lipoma with the presence of mature cartilage islands.

Two mechanisms are accused in the pathogenesis of chondrolipoma; one is the formation of fat tissue as a result of cartilage and bone metaplasia due to mechanical stress or malnutrition. Chondrolipomas close to the bone or joint can develop in this way $(9,10)$. The second theory is the development of the cartilage tissue inside fat tissue as a result of the transformation of multipotent cells to cartilage inside the mesenchyme. Chondrolipomas that develop in this way can be seen anywhere in the body where lipomas may be located and it may not be necessary to wait for many years for their development (10). The second theory was thought to be more valid in the formation of the congenital mass in this case. It is understood that this cartilage metaplasia can also be congenital from a single case where several immunohistochemical markers were examined in the literature (11). Growth factor related proteins such as growth factor- $\beta$, latent growth factor- $\beta$ binding protein-1 transforming, and bone morphogenetic protein have been reported to help understand the pathophysiology of chondrolipoma in this study. Unfortunately no immunohistochemical study could be performed in this case as with almost all head and neck region chondrolipoma cases in the literature.

Chondrolipomas are treated by surgical excision (10). No recurrence was found in the 15-month follow-up after total excision in our case, in accordance with the literature. Despite their characteristic pathology appearance, chondrolipomas can be confused with different variants of lipomas. They can especially be be confused with chondroid lipoma and chondroma of soft tissue $(2,9,12)$. The most important feature in the differential diagnosis with chondroid lipoma is the mature real hyaline cartilage tissue inside the normal fat tissue in chondrolipoma $(2,12)$. There is no real hyaline cartilage in chondroid lipoma and the mature fat cells are dispersed in a chondromyxoid/myxohyaline matrix.

In conclusion, a different lesion was added to the list of differential diagnosis of congenital masses in the neck in childhood with this chondrolipoma case in a previously unidentified location. Besides, the congenital presence of this mass will support the theory of formation of cartilage in fat tissue for chondrolipoma and guide future immunohistochemical studies to determine its pathogenesis.

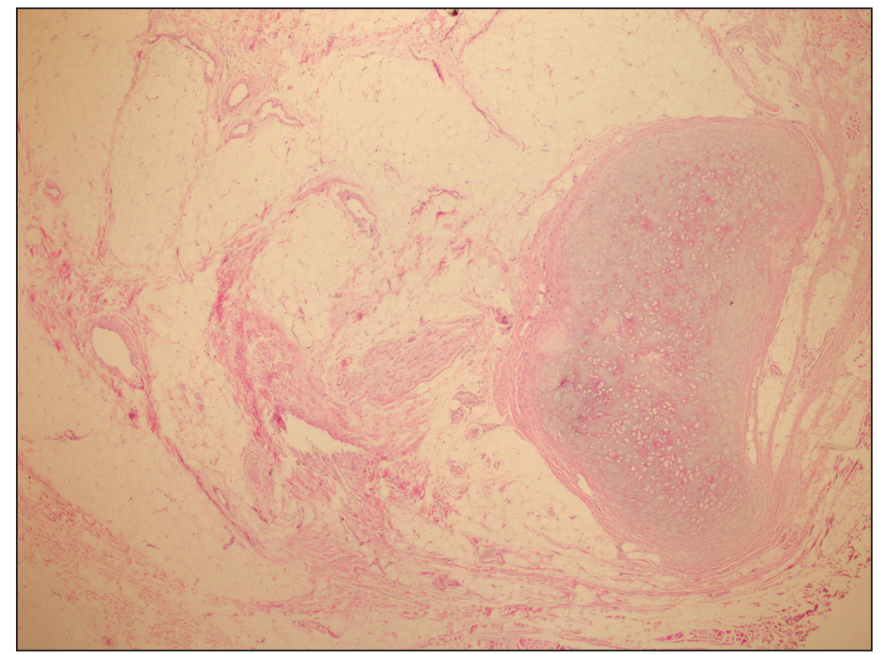

Figure 1: Mature cartilage islands in areas of lipoma surrounded by a thin fibrous capsule, (H\&E x40).

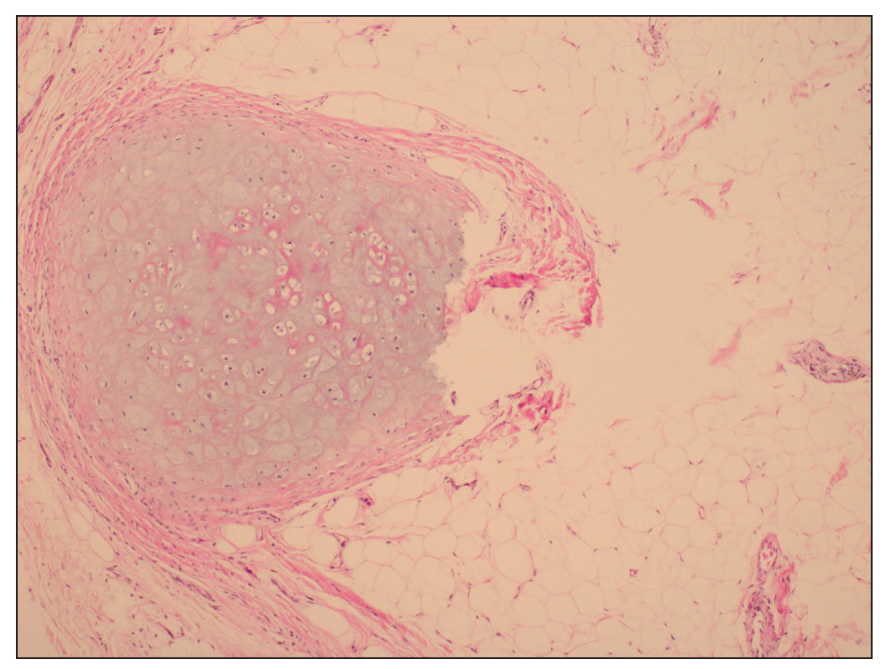

Figure 2: Mature cartilage islet within the area of lipoma at larger magnification ( $\mathrm{H} \& \mathrm{E} \times 100)$.

Table I: Congenital masses located in the lateral neck

Cyst or fistula from the first branchial cleft

Cyst or fistula from the second branchial cleft

Thymic Cyst

Cystic Hygroma

"Olive" due to muscular torticollis

Infantile desmoid fibromatosis

Intramuscular lipoma 


\section{REFERENCES}

1. Goel G, Khadilkar UN, Kumar S. Chondrolipoma of the tongue. Kathmandu Univ Med J. 2008; 6: 505-7.

2. Nonaka CF, Miguel MC, de Souza LB, Pinto LP. Chondrolipoma of the tongue: A case report. J Oral Sci. 2009; 51: 313-6.

3. Hietanen J, Mäkinen J. Chondrolipoma of the tongue. A case report. Int J Oral Maxillofac Surg. 1997; 26: 127-8.

4. Vázquez Rueda F, Salas Molina J, Perez de Sobrino R, Ocaña JM. Chondrolipoma of the tongue in an infant: A case report. An Esp Pediatr. 1993; 39: 553-4.

5. Batchvarova Z, Kadlub N, Coulomb-L'Hermine A, Picard A, Galliani E. Giant chondrolipoma of the tongue in a 14-year-old child with mandibular hypertrophy. Isolated lesion or regional overgrowth. Int J Oral Maxillofac Surg. 2012; 41:261-4.

6. Yllmaz T, Konjenital boyun kitleleri. Türkiye Klinikleri KBB Dergisi. 2003; 3:128-36.

7. Ekinci S, Karnak I, Tanyel FC. Infantile fibromatosis of the sternocleidomastoid muscle mimicking muscular torticollis. J Pediatr Surg. 2004; 39:1424-5.
8. Sohn WI, Kim JH, Jung SN, Kwon H, Cho KJ. Intramuscular lipoma of the sternocleidomastoid muscle. J Craniofac Surg. 2010; 21:1976-8.

9. Pitman KT, Bell D. Chondrolipoma of head and neck: Case report and review of literature. Head Neck. 2013; 35:E18-20.

10. Shabbir F, Greenwood M. Chondrolipoma presenting as a lump on the lateral tongue. Dent Update. 2011; 38:188-90.

11. Nakano M, Arai E, Nakajima Y, Nakamura H, Miyazono K, Hirose T. Immunohistochemical study of chondrolipoma: Possible importanceof transforming growth factor (TGF)-betas, latent TGF-beta binding protein-1 (LTBP-1), and bone morphogenetic protein (BMP) for chondrogenesis in lipoma. J Dermatol. 2003; 30:189-95.

12. Bezerra MF, Costa FW, Pereira KM, Cavalcante RB, Pouchain EC. Chondrolipoma of the Posterior Tongue. J Craniofacial S. 2010; 21:1982-84. 